NBER WORKING PAPER SERIES

A MAJOR RISK APPROACH

TO HEALTH INSURANCE REFORM

\author{
Martin Feldstein \\ Jonathan Gruber
}

Working Paper No. 4852

\author{
NATIONAL BUREAU OF ECONOMIC RESEARCH \\ 1050 Massachusetts Avenue \\ Cambridge, MA 02138 \\ September 1994
}

We are very grateful to Jeffrey Geppert and Kate Baicker for their expert manipulation of the National Medical Expenditure Survey, Daniel Feenberg for help with the TAXSIM calculations reported in section 5, and to members of the NBER Health Care Program for comments. The current paper should not be construed as a proposal or as an advocacy for any particular insurance reform but only as an analysis of some of the consequences of alternative major risk insurance plans. This paper is part of NBER's research programs in Health Care, Health Economics and Public Economics. Any opinions expressed are those of the authors and not those of the National Bureau of Economic Research.

- 1994 by Martin Feldstein and Jonathan Gruber. All rights reserved. Short sections of text, not to exceed two paragraphs, may be quoted without explicit permission provided that full credit, including notice, is given to the source. 


\title{
A MAJOR RISK APPROACH \\ TO HEALTH INSURANCE REFORM
}

\begin{abstract}
This paper examines the implications of a "major-risk" approach to health insurance using data from the National Medical Expenditure Survey. We study the impact of switching from existing coverage to a policy with a 50 percent coinsurance rate and 10 percent of income limit on out-of-pocket expenditures, as well as several alternative combinations of a high-coinsurance rate with a limited out-of-pocket payment. Our analysis is limited to the population under age 65 ,

Although 80 percent of spending on physicians and hospital care is done by the 20 percent of families who spend over $\$ \mathbf{5 , 0 0 0}$ in a year, our analysis shows that shifting to a major risk policy could reduce aggregate health spending by nearly 20 percent. The reductions would be greatest among higher income individuals.

By reducing the excess consumption of health services, the major risk policy increases aggregate economic efficiency. The extent of the increase in efficiency depends on demand elasticities and the extent of risk aversion. With modest values of both demand sensitivity and risk aversion, we find that shifting to a major risk policy would raise aggregate national efficiency by $\$ 34$ billion a year. Greater demand sensitivity and/or greater risk sensitivity imply even larger gains.

Government provision of a major tisk policy to everyone under the age of 65 could be financed with a premium of about $\$ 150$ per person because of the increased tax revenue and reduced Medicare outlays that would result from the provision of universal major risk insurance for the population under age 65 . Even without govemment provision, individuals might be induced to select major risk policies by changing existing tax rules to eliminate the advantage of insurance, either by including employer provided insurance in taxable income or by permitting a tax deduction for out-of-pocket medical expenditures.

Martin Feldstein

National Bureau of Economic Research 1050 Massachusetts Avenue

Cambridge, MA 02138

and Harvard University

Jonathan Gruber

Department of Economics, ES2-274c Massachusetts Institute of Technology Cambridge, MA 02139 and NBER
\end{abstract}




\section{A Major Risk Approach to Health Insurance Reform}

\section{Martin Feldstein and Jonathan Gruber'}

The purpose of insurance is to protect individuals against unexpected expenses. At the same time, the presence of insurance alters the behavior of the insured in ways that increase the expected magnitude of losses. Designing the optimal insurance policy therefore involves balancing the gains from protection against the losses that result from the distortion of behavior. ${ }^{2}$

The character of actual health insurance in the United States reflects not only the balancing of protection and distortion but also the special incentives created by the tax law. The U.S. ax law permits employers to deduct their payments for health insurance as a cost of business while excluding those premiums from the taxable income of employees. This rule substantially lowers the individual's cost of employer-provided health care through insurance. For an individual with a 30 percent marginal tax rate, a one dollar health insurance premium costs only 70 cents of after-tax income. This makes it personally optimal to have much more

\footnotetext{
'Martin Feldstein is Professor of Economics at Harvard University and President of the NBER. Jonathan Gruber is Assistant Professor of Economics at MIT and a Faculty Research Fellow of the NBER. We are very grateful to Jeffrey Geppert and Kate Baicker for their expert manipulation of the National Medical Expenditure Survey, Daniel Feenberg for help with the TAXSIM calculations reported in section 5, and to members of the NBER Health Care Program for comments. The current paper should not be construed as a proposal or as an advocacy for any particular insurance reform but only as an analysis of some of the consequences of alternative major risk insurance plans.

${ }^{2}$ On the general problem of the design of optimal insurance, see Borch (1968), Gouid (1969), Mossin (1968), Pashigian et al. (1966), and Smith (1968); the theory is reviewed in Laffont (1990). Some of the specific problems of designing bealth insurance are discussed in Arrow (1963) and Zeckhauser (1970).
} 
complete insurance than would otherwise be chosen. ${ }^{3}$

This more complete insurance results in higher spending on medical care, and an increased welfare loss from insurance. An individual with a 20 percent coinsurance rate increases health care spending until the last dollar of services brings a benefit that the individual values at only 20 cents. Since the cost of providing that dollar of services is a dollar, there is an 80 cent welfare loss on that last dollar of spending. Because the extent of the distortion in the structure of insurance (i.e., in the coinsurance rate) can be very substantial, the welfare loss that results from the excessive health care spending can also be very large.

In an earlier paper, Feldstein (1971a) suggested that an insurance policy that combined a 50 percent coinsurance rate with a maximum out-of-pocket limit of 10 percent of income would cause most individuals to be more sensitive than under existing insurance to the costs of health care while protecting them against the financial hardship that would result from medical expenses that are a very large share of income. The present paper examines the implications of such a "major risk insurance" approach in the context of today's medical marketplace. More specifically, we use newly available data on health care spending collected by the National Medical Expenditure Survey (Agency for Health Care Policy and Research, 1991) to answer four questions:

(1) Given the existing distribution of health care spending, is it possible to limit total out of pocket spending to a moderate percent of income while still having a sizeable fraction of

${ }^{3}$ Feldstein and Allison (1974) discuss the relation between the tax exclusion and insurance coverage. An explicit calculation of the effect of the exclusion on the individually optimal level of insurance is presented in Feldstein and Friedman (1977). More recent research on the relation between tax rules and health insurance includes Gruber and Poterba (1994a,b).

"Feldstein (1973) discusses the welfare cost of excess health insurance. 
health spending done by individuals who are facing a large coinsurance rate on the margin? Although this seemed plausible in the early 1970 s, reliable data were not available to answer the question. Moreover, because health care costs have risen much faster than income since 1970 , an out-of-pocket spending limit of 10 percent of income and a 50 percent coinsurance rate might leave too many peopie at the limit to provide a useful overall incentive to reduce excessive health care spending.

(2) How would a major risk insurance structure with a high coinsurance rate and an income related out-of-pocket maximum affect individuals at different income levels?

(3) What are the explicit welfare effects of shifting from existing insurance coverage to major risk insurance? Substituting a major risk insurance policy would reduce the welfare loss that now results from consuming health care services that are worth less than they cost to produce. But the effect on the risk that individuals bear is ambiguous. The higher coinsurance rate would increase the amount of out-of-pocket risk for many individuals. For them, the gain in reduced distortion must be balanced against the loss of increased risk bearing. For some individuals, however, the maximum-out-of-pocket limit would lower their risk so that the gain from decreased risk bearing would reinforce the gain from reduced distortion. The extent of these gains and losses depends on the distribution of income and spending and on the parameters of demand and of risk aversion that are discussed below.

(4) Could a publicly provided major risk insurance policy be financed by eliminating the current favorable tax treatment of health insurance premiums paid by employers? 


\section{The National Medical Expenditure Survey Data}

The present analysis utilizes a remarkable body of data collected by the Agency for Health Care Policy and Research in 1987. The National Medical Expenditure Survey (NMES) began with a population sample in which individuals were asked about their consumption of healch services, and about the identity of their employers and insurance companies (if they purchased insurance on their own). Employers and insurers were then asked for deails on the individual's insurance plan. Interviews with providers were used to obtain detailed information on the utilization of insured health services to supplement the information reported by the individuals themselves. ${ }^{5}$

In order to have a distribution of health spending that represents what a well insured family or individual would spend, we have restricted attention to families in which all members are covered by a private group insurance policy. Our sample is also restricted by eliminating any insurance unit with someone who is over 65 years old (since they would be covered by the Federal government's Medicare program.)

The resulting sample has 6,000 insurance units, either individuals or families. ${ }^{6}$ We use the NMES weights on these observations to reweight our sample by income and demographic

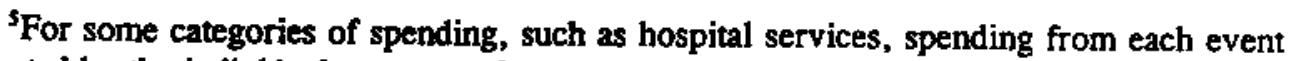
reported by the individuals was corroborated with the provider. For other categories, such as physician visits, only a subsample of spending events were corroborated, and the resulting evidence was used to adjust reported spending for the remaining events.

${ }^{6}$ An insurance unit can be an individual or a Census family or any subgroup that has separate insurance coverage. For example, an adult child living at home would be part of the Census family but would generally be a separate insurance group.
} 
group to obtain national totals with the correct income and demographic mix. ${ }^{7}$ Since the data were collected for 1987, we adjust the individual amounts of income and health care spending to projected 1995 levels. Income are adjusted from 1987 to 1995 by a factor of 1.583 , reflecting the increase in nominal per capita income. Health care spending is adjusted by the growth rate in per capita personal health expenditure on doctors and hospitals as projected to 1995 by the Congressional Budget Office (Congressional Budget Office, 1993).

The weighted mean level of spending in this well insured group of under-65 year olds at 1995 levels was $\$ 3985.8$ The distribution of spending is very skewed. While 39 percent of insurance units spend less than $\$ 500$, their spending constitutes only 1.5 percent of total spending. In contrast, only one-sixth of insurance units spend more than $\$ 5,000$ but their spending constitutes almost 80 percent of total spending. Table 1 presents the distribution of spending, indicating the fraction of insurance units with spending below that limit and the fraction of total health care dollars spent below that limit.

The existing private group insurance policies require insurance units to pay deductibles and coinsurance payments that together represent an average of 39 percent of gross spending on doctors and hospitals. This number is surprisingly high, given the well insured group which we observe.

Table 2 shows the distribution of this out of pocket spending. The distribution is even

'Such a reweighting is important because, for example, our average unweighted sample member is richer than the average population member. We cannot adjust, however, for the possibility of self-selection in either insurance status or in the characteristics of the individual's insurance plan.

"We use the term "health care spending" as a shorthand for the spending on physicians and hospitals. We exclude other categories of spending because they may not be covered by these individuals' private insurance plans. 
more skewed than the total spending distribution, with the top $4 \%$ of spenders accounting for almost $40 \%$ of out of pocket spending. The fact that $83 \%$ of the sample has out of pocket spending below $\$ 1000$ in a year under their existing health insurance plans suggests that there is some scope for demand reduction under an MRI-type plan.

\section{Would a Major Risk Insurance Policy Reduce Excessive Spending?}

The very skewed distribution of health care spending raises the question of whether a limit of 10 percent on the out-of-pocket health spending would leave many dollars of health spending exposed to a substantial co-payment rate. For example, a major risk insurance policy with a 50 percent co-payment rate and an out-of-pocket limit of 10 percent of income would cause a family with $\$ 35,000$ of income to be sensitive on spending below $\$ 7,000$ but then to have a zero marginal price for health spending above $\$ 7,000$. The distribution in Table 1 shows that $68 \%$ percent of spending is incurred by insurance units that spend more than $\$ 7,000$.

More generally, the combination of a 50 percent coinsurance rate and a ten percent maximum out of pocket limit implies that individuals are sensitive if their health spending is less than 20 percent of their income and insensitive if their spending is above that amount. The NMES data imply that only 11 percent of non-aged insurance units spend 20 percent or more of their income on health care but that 64 percent of total spending is spent by that 11 percent. A major risk insurance policy with a 50 percent coinsurance rate and a 10 percent of income maximum out of pocket amount can therefore reduce excessive spending by shrinking the spending of the 89 percent of insurance units who collectively spend 36 percent of the total health 
dollars.

An alternative major risk insurance policy that combines a 50 percent coinsurance rate with a 15 percent of income maximum out of pocket limit impties that individuals would be sensitive on incremental spending if they spend less than 30 percent of their income on health care. According to the NMES data, such a major risk insurance policy would be able to shrink the spending of 92 percent of insurance units who spend 45 of total health spending.

The effect on health care spending of raising coinsurance rates from current levels to 50 percent depends on the price elasticity of demand for health care. Because there is considerable uncertainty surrounding the value of this elasticity, the analysis in this paper examines the implications of elasticities of 0.33 and 0.50 . We believe that these values are likely to be relatively modest as estimates of the long-run response of the health care system to changes in coinsurance rates. ${ }^{20}$

Our analysis assumes that spending in excess of 10 percent of income reverts to the spending under the current insurance coverage. Almost all people with private group insurance

${ }^{9}$ To the extent that individuals reach their spending limit in a series of smaller spending episodes, the 50 percent coinsurance rate will reduce total spending even for the insurance unit that exceeds its maximum out of pocket amount.

to The RAND national health insurance experiment (Manning et al., 1987; Newhouse, 1993) estimated an elasticity of health care spending with respect to the net-of-insurance cost per dollar of care of only $\mathbf{0 . 2}$. We believe that the RAND procedure of giving different insurance coverage to a random sample of individuals is likely to underestimate the effect on utilization of a community-wide change in coinsurance rates. Changing the policy of isolated individuals, as the RAND experiment did, may change the willingness of patients to visit a physician but will not alter the character of the care given prescribed by physicians or the sophistication of the services provided by hospitals. Earlier (non-experimental) literature on the price elasticity of demand for health care is reviewed by Phelps (1992). Estimates of the elasticity of demand for hospital care range from -0.47 (Davis and Russell, 1972) to -0.67 (Feldstein, 1971b), and for doctor care from -0.14 (Newhouse and Pheips, 1971) to -1 (for hospital outpatient visits - Davis and Russell, 1972). 
are already at a zero coinsurance rate when their gross medical spending reaches 20 percent of income, the level at which the 10 percent maximum out of pocket limit in the alternative major risk insurance policy reduces the coinsurance rate to zero. Even though the cash price is then zero, utilization is limited by a combination of provider decisions and patient concerns about the risk, discomfort and time loss associated with increased utilization of care. ${ }^{11}$

Table 3 shows the effect of alternative major risk insurance policies on health care spending, with that spending decomposed to show the amount paid out-of-pocket and by the insurance company. The first line of the table shows the spending under the existing group insurance coverage as reported in the NMES data. ${ }^{\mathrm{t2}}$ The average spending per insurance unit is $\$ 3,985$ (at 1995 price levels). Of this the average out-of-pocket spending is $\$ 747$ and the remaining $\$ 3238$ is paid by the insurers. ${ }^{13}$ These amounts per insurance unit correspond to an aggregate spending on physician and hospital services by the nonaged population of $\$ 329$ billion.

\footnotetext{
"This assumption is subject to two offsetting biases. First, we understate the potential gain from the major risk insurance policy by assuming (in effect) that there is only one "draw" from the distribution of medical spending per year. A more realistic picture for spending is one of a series of smaller spending decisions throughout the year. In this case, spending on the "early" events will be reduced by the $50 \%$ coinsurance rate under the MRI plan, even if that family eventually exceeds the maximum out of pocket amount. On the other hand, for some low income individuals, the maximum out of pocket amount may be below the maximum which the family faced under their ex-ante insurance plans. For those persons, we do not account for the fact that we are lowering their price to zero above $20 \%$ of their income, so that we overstate the gains from a major risk policy.

${ }^{12}$ Recall that we are analyzing only those nonaged individuals and families in the NMES data that have group insurance and that this subsample of the population is then reweighted to correspond to the national nonaged population. Estimates are presented for national aggregate spending and for spending per "insurance unit". The insurance units are the actual individuals and families that are separately insured in the NMES sample.

${ }^{13}$ It is interesting to note that, despite that fact that the average coinsurance rate under existing private insurance plans in our sample is almost $40 \%$, the average out of pocket amount is less than $20 \%$ of the average total spending. This reflects the fact that the distribution of out of pocket spending is even more skewed than the distribution of total spending.
} 
The next three lines show the effect of the basic 50-10 major risk insurance plan that has a 50 percent coinsurance rate on all spending until out of pocket spending reaches 10 percent of income. With a zero price elasticity the only effect of the major risk policy is to shift the burden of the cost from the insurance company to the individuals. Aggregate out of pocket payments rise by 51 percent from $\$ 61.1$ billion to $\$ 93.0$ billion but there is no change in the $\$ 328.7$ billion total cost of care.

With a price elasticity of 0.33 , aggregate total spending falls by $\$ 60$ billion to $\$ 268.7$ billion, a decline of 18 percent. It is striking that even though the higher coinsurance rate applies to only 36 percent of spending and the elasticity is a modest 0.33 , the major risk policy reduces total spending by $\$ 60$ billion a year or 18 percent of the aggregate baseline spending. Because total spending is rectuced, out of pocket spending is only 17 percent higher, rising from $\$ 747$ per insurance unit under the existing policy to $\$ 873$ per insurance unit under the major risk policy.

A long-run price elasticity of 0.50 implies that, in the long run, a major risk policy would reduce total spending by 31 percent or $\$ 101$ billion a year. With this elasticity, there is essentially no increase in out of pocket spending. The decline in the total spending almost exactly balances the increased share paid out of pocket, causing the out-of-pocket amount per insured to rise from $\$ 747$ to only $\$ 768$. The amount paid by the insurers, and therefore the insurance premium, declines by $\$ 1,248$ per insurance unit or 39 percent.

Thus, even with the very skewed distribution of health spending that we now observe, the major risk structure of a high coinsurance rate and a 10 percent of income limit on out-of-pocket spending can reduce total spending very substantially and leave average out of pocket spending unchanged, if the demand elasticity is as high as 0.5 .

The next three lines of Tabie 3 show the effect of increasing the maximum out of pocket 
amount to 15 percent of income while keeping the coinsurance rate at 50 percent. Since this 50 percent increase in the maximum out of pocket limit only increases the number of cost sensitive insurance units from 89 percent of all units to 92 percents and only increases the fraction of spending that is cost sensitive from 36 percent to 45 percent, the effect on total spending is relatively small. With a price elasticity of 0.5 , aggregate total spending is $\$ 211$ billion or $\$ 16$ billion less than with a 10 percent of income out of pocket limit. Average out of pocket spending rises to $\$ 828$.

One final alternative worth considering is a deductible plan. The last three lines refer to a plan with a deductible (i.e. a 100 percent coinsurance rate) equal to 15 percent of family income. The insured are subject to the same maximum risk as under the 50-15 plan but are sensitive over a much smaller range of costs (up to 15 percent of income instead of 30 percent). Although the sensitivity range is smaller, the 100 percent coinsurance rate makes the individuals more responsive within this range. This greater sensitivity does outweigh the narrower range of sensitivity, causing total spending to be nearly $\$ 17$ billion lower under the 100-15 plan than under the 50-15 plan. Although this total cost saving is achieved without exposing individuals to a higher maximum out of pocket spending than under the $50-15$ plan, the use of the deductible rather than the $\mathbf{5 0}$ percent coinsurance rate increases the average out of pocket spending from $\$ 828$ per insurance unit to $\$ 1100$ per insurance unit. This is because the deductible plan increases the out of pocket spending in the more likely part of the spending distribution.

Before presenting an explicit welfare analysis that combines the effects of the reduced distortion (i.e., the lower total spending) and the changes in individual risk bearing, we look briefly at the way that the major risk policies affect individuals at different income levels. 


\section{How Does Major Risk Insurance Affect Different Income_Groups?}

Because the maximum out of pocket payment is limited to 10 percent of income, the major risk policy pays substantially more for lower income individuals and families than it does for higher income groups. In comparison to the existing structure of insurance, the result is a substantial redistribution in favor of lower income groups. This redistribution is in addition to any redistribution that occurs in extending coverage to those low income individuals who are currently uninsured.

Table 4 divides the population into four different income groups and shows for each group the patterns of spending under the existing insurance coverage and under the 50-10 major risk plan. Before examining the effect of the major risk insurance, it is worth noting that the average level of spending under the initial insurance coverage differs substantially among the four income groups. The group of individuals below poverty has by far the highest initial level of spending per insurance unit. This may be a reflection of the way that these data are constructed rather than an accurate picture of the spending of below poverty groups in the population as a whole. The data presented here are based on the rather unlikely combination of being below poverty but still insured by a private group policy. One way that individuals might find themselves in such a situation is by becoming very ill while working for a firm that provides group insurance, causing them to leave their jobs, but retain their health insurance. ${ }^{14}$ This

${ }^{14}$ Federal legislation under the Consolidated Omnibus Reconciliation Act of 1986 (COBRA) mandated that individuals who left jobs where they were covered by health insurance plans could continue to purchase that insurance at the average group rate. Huth (1991) and Long and Marquis (1992) find that such continuation coverage is in fact taken up by the sickest job leavers. 
distortion of the baseline spending pattern changes the specific numerical values presented in the current section but does not alter the basic conclusion that major risk policies are particularly favorable to lower income individuals. ${ }^{15}$

Two features stand out in Table 4. First, the average out of pocket spending under the major risk plan rises very sharply as income rises, reflecting the fact that the maximum out of pocket spending rises in proportion to income. With no behavioral response, the average out of pocket spending rises from $\$ 421$ in the below poverty group to $\$ 908$ in the group between poverty and twice poverty and eventually to $\$ 1893$ in the highest income group. In the lowest income group the average out of pocket spending under the major risk plan is less than one third of the baseline level under the ex-ante insurance policy while in the highest income group the average spending under the major risk plan is more than twice the baseline level.

Although the behavioral response to higher coinsurance diminishes the strength of this effect, it remains true even with a price elasticity of 0.5 . Out of pocket spending goes from less than one third of the baseline level in the below poverty group to 30 percent above the baseline level in the highest income group.

The second noticeable feature is that the major risk plan reduces the total consumption of health care much more for high income individuals than for lower income individuals. This reflects the fact that the higher coinsurance rate applies to an increasing share of spending as income rises. With a price elasticity of 0.5 the lowest income group sees total aggregate health

\footnotetext{
${ }^{15}$ As a check on the results in this section, we have prepared estimates of the distributional effect of the income-related out-of-pocket maximum for a "synthetic" population that is assumed to have the same random distribution of spending for each demographic group regardless ofincome, thus purging the data of the problematic correlation between spending and income documented in Table 3. The method of doing this analysis and the results are presented in the Appendix to this paper. Those results confirm the general characteristics described in this section of the paper.
} 
spending decline by only 7.4 percent (from $\$ 44.5$ billion to $\$ 41.2$ billion). Among those with incomes between poverty and twice poverty health spending declines by 26 percent and in the highest income group it declines by 44 percent. Thus, the MRI plan reduces total spending in a way that favors lower income individuals or families.

\section{The Welfare Economics of Major Risk Insurance ${ }^{16}$}

Substituting a major risk policy for existing health insurance has two effects on individual welfare. It reduces the deadweight loss that results from the excessive consumption of health care services induced by the very low marginal cost of care under existing insurance policies. It also alters the risk distribution that the individual faces, increasing the risk of modest spending but limiting the maximum risk. The reduction in the deadweight loss is an unambiguous benefit while the sign of the welfare effect of the change in the risk distribution is ex ante ambiguous, depending on the distribution of health care spending and on the individual's utility function.

We simplify the welfare calculations by assuming that the two welfare effects can be evaluated separately and added together. We also convert the welfare changes into equivalent income variations and then aggregate by adding those equivalent income variation measures over all insurance units in the population.

${ }^{16}$ This section follows the approach developed in Feldstein (1973). A major difference is that the current paper uses the actual distribution of gross spending while Feldstein (1973) used very aggregate data to estimate the probability of hospital admission and the parameters of a gamma distribution which was taken to represent the conditional distribution of spending. In order to make the analysis tractable with the resulting mixed poisson-gamma distribution process, the utility function had to be assumed to be one of constant absolute risk aversion. 


\subsection{The Reduced Distortion of Health Care Spending}

Figure 1 shows our approach to measuring the individual gain from reduced distortion. We measure the unit of health care so that its price in the absence of insurance is $1 .^{17}$ The existing insurance policy has a coinsurance rate of $P_{0}$, which is the net of insurance price to the consumer. Conditional on the individual's medical condition, the individual consumes $E_{0}$ units of care. The deadweight loss caused by the induced increase in health spending is given by the area of the triangle $\mathrm{ACD}$.

The major risk policy raises the coinsurance rate for that individual to $\mathrm{P}_{1}$ (if the resulting out of pocket cost is below the maximum out-of-pocket amount) and reduces the consumption of health care to $E_{1}$ This reduces the deadweight loss by the shaded area $B C D E$, which is equal to $\left(E_{0}-E_{1}\right)^{*}\left(1-P_{1}\right)+0.5 *\left(P_{1}-P_{0}\right) *\left(E_{0}-E_{1}\right)$.

The reduction in the deadweight loss implied by the simple analysis of Figure 1 varies from individual to individual, depending on the individual's medical condition and therefore on the initial level of health care spending, $\mathrm{E}_{0}$. For each individual, the reduction in the deadweight loss is readily calculated for any major risk coinsurance rate $\left(P_{1}\right)$ on the basis of the available data ( $E_{0}$ and $P_{0}$ as reported in the NMES survey) and the assumed price elasticity of demand since $E_{1}=E_{0}\left(P_{0} / P_{1}\right)^{x}$ where $\epsilon$ is the absolute value of the price elasticity. As noted earlier, if the individual's spending is over the maximum out of pocket level, our analysis assumes that the major risk insurance policy has no effect on utilization and therefore no effect on the deadweight

\footnotetext{
${ }^{17}$ Our analysis assumes that health care services are supplied at constant cost so that no change in producers' surplus need be taken into account.
} 
loss.

Even at our highest elasticity assumptions, there is a further reason why our calculation may understate the gain from reduced spending in the long run. The initial level of spending may exceed what consumers would really want even at the initial price because the physicians who make the detailed health care choices, instead of acting as the agents of their patients, prescribe additional care. Such excessive care could arise because of a concern about medical malpractice, physician preferences for practicing a technically more sophisticated style of medical care, or because it is in the physician's own financial interest to prescribe more extensive care. With increased patient cost sharing, patient sensitivity to the increased costs of care arising from such physician behavior may counteract these supply side tendencies.

\subsection{The Change in Risk Bearing}

To calculate the effect of the change in the individual's risk bearing we ask, for each insurance unit in our sample, what that unit would have to be paid to assume the additional risk implied by the increased coinsurance rate (or would pay if the risk-limiting effect of the maximum out of pocket limit outweighs the increased risk of the higher coinsurance rate). We then aggregate these amounts over the population as a whole.

More formally, we assume that each individual has utility which is a function of net non-

18 Once again, our analysis may understate the potential gain from the major tisk insurance policy by assuming that there is only one "draw" from the distribution of medical spending per year. A more realistic picture in which spending for the year is the result of a series of spending decisions creates the possibility that total spending will be reduced even though the individual eventually spends enough to exceed the maximum out of pocket limit since the "early" spending decisions in the year were influenced by the high coinsurance rate. 
health consumption, defined as the difference between that individual's income ( $\left.\mathrm{Y}^{\prime}\right)$ and the random out of pocket expenditure $\mathrm{X}_{0}{ }_{0}$ : that is, $\mathrm{U}\left(\mathrm{Y}^{\mathrm{j}}-\mathrm{X}_{0}{ }^{\mathrm{i}}\right)$. The expected utility of the individual is thus $\mathbf{E}\left\{U\left(Y^{i}-X_{0}{ }^{i}\right)\right\}$ where the expectation is over the different possible values of $X_{0}{ }^{\prime}$. The uncertain distribution of out of pocket payments can be summarized by the certainty equivalent $C_{0}{ }^{i}$, a fixed amount such that $\left.U\left(Y^{i}-C_{0}{ }^{j}\right)\right\} .=E\left\{U\left(Y^{j}-X_{0}{ }^{i}\right)\right\}$.

The shift to the major risk policy replaces each individual's out-of-pocket distribution $\mathrm{X}_{0}{ }^{i}$ with a new out-of-pocket distribution $\mathbf{X}_{1}{ }^{i}$. Since the difference between the mean values of $\mathbf{X}_{0}{ }^{i}$ and $\mathrm{X}_{1}{ }^{\prime}$ is simply a transfer between the insured and the insurer, we calculate the certainly equivalence of the new out of pocket risk distribution with an adjustment $\left(\mu_{1}{ }^{\prime}-\mu_{0}{ }^{\prime}\right)$ to make the mean of the new risk distribution equal to the mean value of the initial distribution (that is, we evaluate the mean preserving spread in risk). Thus we define the certainty equivalence payment $C_{1}{ }^{i}$ as : $\mathbf{E}\left\{\mathrm{U}\left(\mathbf{Y}^{\mathbf{i}}-\mathbf{X}_{1}{ }^{i}+\mu_{1}{ }^{i}-\mu_{0}\right)\right\}=U\left(Y^{i}-C_{1}{ }^{i}\right)$.

The difference between the two certainty equivalence values, $\mathrm{C}_{1}{ }^{i}-\mathrm{C}_{0}{ }^{1}$, measures the change in the value that the individual attributes to risk-bearing. We add these certainty equivalence differences over individuals just as we added the value of the reduced distortion.

To make this approach operational, we need to specify a particular utility function and a method of calculating expected utility. Our analysis uses the constant relative risk aversion utility function $\mathrm{U}(\mathrm{Z})=-(1 / \rho) \mathrm{Z}^{\rightarrow}$, which implies that the relative risk aversion is $-\mathrm{U}^{n} / \mathrm{Z} \mathrm{U}^{\prime}=\rho+1$. A special case of this, the logarithmic utility function $U(Z)=\ln Z$, corresponds to $\rho=0$. For our numerical calculations, we examine two values of risk aversion: the logarithmic case with constant relative risk aversion of 1 and the more risk averse case with constant relative risk aversion of $3(\rho=2)$. These values essentially contain the range of estimated coefficients of relative risk aversion in the macroeconomics literature (Zeldes, 1989). 
To calculate expected values we first create distributions of spending under the existing insurance for each of four demographic types of insurance units in our NMES data: single adults; single adults with children; couples ; and couples with children. To create each distribution, we rank all of the observations of that demographic type, divide the rank list into one hundred equal intervals, and assign a probability of 0.01 to each interval. To calculate the expected utility for each individual under the initial insurance, $\mathbf{E} U\left\{\mathrm{Y}-\mathrm{X}_{0}\right\}$, we draw fifty observations from the relevant demographic distribution and calculate the average utility for that insurance unit (given its income). In this way we combine the (reweighted) income distribution of the NMES data and the demographic-specific cumulative frequency distributions of spending. ${ }^{19}$ To calculate expected utility for any major risk insurance plan we repeat the same process with the additional step of transforming the out of pocket spending from the initial level to the level corresponding to the major risk coinsurance rate and elasticity of demand.

\subsection{Results}

The results of the analysis are presented in Table 5 for the three major risk plans and demand elasticity values that we considered in Table 3 and for the two different measures of constant relative risk aversion. Consider first the welfare gain from reducing the insurance-

${ }^{19}$ Our method assumes that the distribution of spending within each demographic group is independent of the level of income. An alternative procedure of grouping individuals by broad income group as well as demographic group would allow us to relax this assumption but, by giving us a smaller sample for each group, would make the resulting distribution less reliable. Because of the importance to our analysis of the relatively infrequent large expenditures, we have chosen to use the larger samples to calculate the cumulative distributions for each demographic group rather than recognizing the possible relation between income and spending. 
induced distortion of demand. The first row of the table is based on the 50-10 major risk plan with a zero price elasticity of demand and a constant relative risk aversion of 1 . Since the zero price elasticity implies that shifting from existing insurance to the major risk plan involves no change in behavior, there is no welfare gain from reduced distortion. With a demand elasticity of 0.33 , shown in the next row, there is a reduced distortion. The reduced deadweight loss is equal to $\$ 534$ per insurance unit, approximately 13 percent of the initial spending level and 73 percent of the reduced spending shown in Table 3. A demand elasticity of 0.5 increases the value of the reduced distortion to $\$ 902$ per insurance unit.

The major risk plan with a 50 percent coinsurance rate but a wider range of sensitivity corresponding to a maximum out of pocket limit of 15 percent of income causes slightly greater reductions in distortion. With an elasticity of 0.5 , the value of the reduced distortion is $\$ 1045$ per insurance unit (instead of the $\$ 902$ reported for the 50-10 policy.)

Replacing the 50 percent coinsurance rate with a deductible equal to 15 percent of income (the 100-15 plan) causes lower average levels of spending (as indicated in Table 3) but reduces the average deadweight loss of distortion by less. For example, with an elasticity of 0.5 the $50-$ 15 plan reduces average spending relative to the initial level by $\$ 1426$ while the $100-15$ plan reduces average spending $\$ 1629$. In contrast, the value of the reduced distortion associated with the 50-15 plan is \$1045 while the value of the reduced distortion associated with the 100-15 plan is only $\mathbf{\$ 7 3 5}$. The reason that the deductible reduces spending by more but the deadweight loss by less is that deductibles reduce spending within a smaller range. Since some of the spending in that range was valued by the consumer, the reduced DWL per dollar of reduced spending is smaller. That is, it is more efficient to maintain a high price on the marginal dollar of spending than to cut spending deeply over a small range, with a price of zero above that range. 
To assess the overall welfare effect of shifting from existing insurance to a major risk plan, these reductions in deadweight loss must be combined with assessments of the change in risk. Consider first the case of the 50-10 major risk plan with logarithmic utility function $($ CRRA $=1)$. If the demand elasticity is zero (the fist row of table 5), each individual faces the increased risk associated with a higher coinsurance rate up to the maximum out of pocket limit but then may have less risk than under the existing ordinary insurance plan. On average, individuals would be indifferent between the new and riskier distribution and the initial distribution plus a certainty equivalent charge of $\$ 317$. The net welfare effect of the major risk insurance plan when individuals have a zero demand elasticity is therefore an average loss of $\$ 317$ per insurance unit.

The next row of Table 5 shows that the result is quite different when the individuals have a demand elasticity of 0.33 . The reduced distortion of $\$ 534$ outweighs the increased risk valued at $\$ 317$, producing a net gain of $\$ 217$ per insurance unit. This understates the true net welfare gain associated with the elasticity of 0.33 because the behavioral response reduces the amount of out-of-pocket risk relative to what it would be with no behavioral response (as well as reducing the distortion in total spending.) Although the net out-of-pocket risk remains greater with the 5010 plan than with the existing plan, the combination of the greater coinsurance rate and the reduction in total spending implies that the increased risk has a certainty equivalent charge of only $\$ 118$. This is shown in the second column of Table 5. Subtracting the value of the increased risk from the value of the reduced distortion leaves a net gain of $\$ 416$ per insurance unit. Since there are 82.5 million insurance units, this implies an aggregate welfare gain of $\$ 34.3$ billion (shown in the last column of table 5 ).

An elasticity of 0.5 implies not only a greater reduction in distortion ( $\$ 902$ per insurance 
unit) but also a much small increase in risk ( $\$ 42$ per insurance unit), implying a net gain from shifting to the 50-10 major risk policy of $\$ 860$ per insurance unit and an aggregate net gain of $\$ 71.0$ billion.

Although extending the sensitivity range by increasing the maximum out of pocket amount to 15 percent of income (the 50-15 major risk plan) reduces distortion by more than the 50-10 plan, the gain from this source is not enough to outweigh the increased risk bearing when the demand elasticity is 0.5 or less. With an elasticity of 0.5 , the reduced distortion is $\$ 1045$ and the increased risk bearing is $\$ 201$, implying a net gain of $\$ 844$, slightly below the $\$ 860$ net gain of the 50-10 plan. Comparing the two plans shows that the gap decreases as the demand elasticity increases, from a gap of $\$ 217$ with no behavioral response to $\$ 21$ when the demand elasticity is 0.33 and $\$ 16$ when the demand elasticity is 0.5 . The 50-15 plan only produces a greater benefit when the dernand elasticity exceeds $\mathbf{0 . 6 5}$.

Substituting a deductible for the 50 percent coinsurance rate is clearly inferior. Not only is the reduced distortion less for each demand elasticity, as noted above, but the value of the increased risk is also greater.

The lower half of the table considers the welfare effects if individuals are substantially more risk averse (a constant relative risk aversion of $\rho+1=3$.) The striking difference between the logarithmic utility function and this case is that there is actually reduced risk bearing in the cases of 0.33 and 0.5 elasticity, with both the 50-10 and 50-15 plans. That is, in these cases, the reduced risk associated with the maximum out of pocket limit now outweighs the increased risk below that limit.

In fact, even with no behavioral response, the increased protection afforded by the 10 percent of income limit on out of pocket expenses outweighs the shift to the 50 percent 
coinsurance rate under the $50-10$ plan and produces a net gain of $\$ 154$ per insurance unit. With a zero price elasticity, individuals would on average be indifferent between the out-of-pocket risk distribution of the 50-10 major risk policy and the combination of the current insurance policy and paying a fixed lump sum of $\$ 154$.

An increase in the price elasticity of demand shrinks the amount of risk with the 50-10 plan and therefore makes the risk reduction even greater; with an elasticity of 0.5 , the reduced risk of the 50-10 plan is worth $\$ 442$ per insurance unit. Combined with the distortion reduction worth $\$ 902$ per insurance unit, the total gain is $\$ 1344$ per insurance unit or an aggregate of $\$ 110.9$ billion.

The greater risk aversion does not alter the relative attractiveness of the three major risk plans. The 50-10 plan still has a greater welfare gain than the 50-15 plan or the 100-15 plan. Given the plausible range of risk aversion values that we have considered, the analysis of this section implies that the net overall welfare gain of the 50-10 major risk plan is between $\$ 34.3$ billion (with demand elasticity or 0.33 and relative risk version of 1.0 ) and $\$ 110.9$ billion (with a demand elasticity of 0.50 and relative risk aversion of 3.0). The shift to a 50-10 major risk plan would reduce aggregate welfare only with low risk aversion (which reduces the value of the limit on out of pocket spending) and a low elasticity of demand (so that the reduced distortion is small and the distribution of coinsurance payments is not reduced by the major risk plan).

\section{Eliminating the Tax Exclusion to Finance Government Provided Major Risk Insurance}

The effects of major risk insurance on bealth care spending and the welfare gains from 
substituting a major risk plan for existing insurance would be obtained if the major risk policies are privately selected or if they are provided by the government. Eliminating the current income tax exclusion for employer paid health insurance premiums ${ }^{20}$ or providing for tax deductible payments for out of pocket expenses ${ }^{21}$ might be enough to cause individuals and their employers to choose major risk type insurance policies. Alternatively, major risk insurance might be provided by the government, as originally suggested in Feldstein (1971).

This section examines the net cost to the government of financing alternative major risk insurance plans as a function of the elasticity of demand. Table 3 showed that the cost of providing the major risk insurance depends on the design of the insurance and on the elasticity of demand for services. The 50-10 plan with no induced change in demand for health services would have a total cost of $\$ 328.7$ billion of which $\$ 93.0$ billion would be paid out of pocket by individuals at the time of care and the remaining $\$ 235.7$ billion would be paid by the insurer. If however the demand elasticity is 0.5 , the total cost of a $50-10$ plan would be only $\$ 227.5$ billion of which the insurer would pay $\$ 164.2$ billion.

If the government were to provide major risk insurance without charge to the entire population, employers would no longer have a reason to provide compensation in the form of

\footnotetext{
${ }^{20}$ Excluding employer paid health insurance from taxable income gives individuals a strong incentive to pay for bealth care through insurance and therefore to have low coinsurance rates. See Congressional Budget Office (1994) or Gruber and Poterba (1994b) for an analysis of recent legislative proposals to eliminate or limit the exchusion of employer paid health insurance. For earlier discussions of including employer payments for health insurance in taxable wage and salary income, see Feldstein (1973), Feldstein and Allison (1974) and Feldstein and Friedman (1977).
}

${ }^{21}$ Tax deductibility of the out-of-pocket payments could be done directly or through tax deductible contributions to health savings accounts of the type that have recently been proposed. Either way would eliminate the current incentive to buy all health care through insurance. 
health insurance. ${ }^{23}$ These premiums would then be converted to wage and salary income and would therefore be subject to income tax and FICA payroll tax. Calculations using the NMES data and the NBER's TAXSIM model indicate that this would raise $\$ 79.0$ billion in federal taxes at 1995 levels. 23 Eliminating as well the deduction for medical expenditures in excess of $7.5 \%$ of AGI is estimated to reduce the government's tax expenditures by $\$ 4.1$ billion in 1995 (Committee on Ways and Means, 1993).

The introduction of major risk insurance would also affect the outlay side of the federal budget in two important ways. First, the major risk policy would replace the existing Medicaid program for those below age 65 and the non-disabled. In 1995 , this is a projected $\$ 50$ billion, or one-third of total Federal and state Medicaid spending. ${ }^{24}$ Second, the increased cost sensitivity of the nonaged population would alter the cost strucnure of hospitals and the standards for treating

\footnotetext{
${ }^{2}$ Indeed, it would also be necessary to preclude additional insurance by individuals since individual who insured the coinsurance part of the major risk policies would be increasing the value of those policies and the expected cost of providing them. (On the impact of supplementary insurance on the cost of Medicare, see Pauly (1974.) Alternatively, individuals could be permitted to purchase additional insurance but only by paying a supplementary premium that reflects the additional cost of the major risk insurance. It is for this reason that having a publicly provided MRI policy would require removing the exchusion from taxable income of medical expenses above 7.5\% of AGI; this acts as a form of reinsurance which would undercut the gains from MRI.

${ }^{23}$ Evidence in favor of the substitutability between benefits and cash wages is provided in Gruber (1994) and Gruber and Krueger (1991). The NMES data indicate the dollar amount of the health insurance premiums paid by employers for each health insurance unit in 1987 . We have adjusted this to 1995 levels by the actual and projected growth of health care spending per capita. Using the income data in the NMES and the NBER's TAXSIM program, we then calculated the reveme gain that would result from converting these employer paid health premiums to wage and salary income.

2We do not consider MRI's effects on the remainder of the Medicaid program, since most speading on the aged consists of mursing home costs. There may be some effect on the medical treatment of the disabled, leading to an understatement of the Federal and state Medicaid savings in our calculations.
} 
different medical conditions. Assuming that Medicare costs declined in the same proportion as total "private" health care spending (i.e., the spending by the population covered by major risk insurance), the rectuced spending on health care would bring substantial savings in federal outlays. For example, with an elasticity of 0.33 the $50-10$ plan reduces total private spending from $\$ 328.7$ billion under the existing health insurance plan to $\$ 268.7$ billion, a decline of 18 percent. Applying this same decline to the $\$ 174$ billion of Federal spending on Medicare implies an annual saving of $\$ 31.3$ billion at 1995 levels. ${ }^{25}$ This reduction in spending would not only be a source of financing for the major risk plan but also an improvenent in resource allocation since these government insurance programs induce an excess provision of health services in the same way that private insurance does.

Combining the $\$ 83.1$ billion increase in tax revenue and the $\$ 81.3$ billion reduction in government spending provides $\$ 164.4$ billion toward the $\$ 196.7$ billion total cost of providing a 50-10 major risk insurance plan with an elasticity of 0.33 . Although using the income tax or payroll tax to finance the remaining cost of $\$ 32.3$ billion a year (see line 2 of Table 6) would involve new sources of deadweight loss, this loss would almost certainly be less than the $\$ 34.3$ billion aggregate welfare gain associated with the shift to a major risk insurance policy (see line 2 of Table 5). Even this deadweight loss of financing cost be avoided by using a compulsory fixed-price insurance premium. With 82 million insurance units, the cost of financing the $\$ 32.3$ billion shortfatl would be slightly less than $\$ 400$ per year.

Although we have not done a formal analysis, we suspect that a major risk policy with an $\$ 700$ premium would leave almost all caxpayers better off than they are today, a reflection of the

\footnotetext{
${ }^{25}$ We recognize of course that any savings in either private spending or government programs would only evolve over a mumber of years. We state these figures in terms of 1995 dollars even though they would only be fully achieved several years later.
} 
substantial overall net welfare gain of $\mathbf{\$ 3 4 . 3}$ billion. The tangible form of this benefit would be a large increase in net of tax wages (since employers would no longer be spending an average of about $\$ 3200$ a year on insurance premiums) and a possible gain through reduced risk bearing if the individuals are sufficiently risk averse.

A higher price elasticity of dernand for health services reduces the government's net financing costs even further. Indeed, row 3 of Table 6 shows that with a demand elasticity of 0.5 the 50-10 major risk plan could be completely financed by a combination of taxing the wages and salaries that result from eliminating private insurance and the savings in federal government outlays that occur from reduced Medicare and Medicaid spending. The higher demand elasticity reduces the insurer's cost to only $\$ 164.2$ billion and this is more than offset by the combination of the $\$ 83.1$ billion in additional reverue and the $\$ 102.8$ billion in Medicare and Medicaid savings.

\section{Conclusions}

The analysis presented in this paper shows that a health insurance plan that has a 50 percent coinsurance rate but limits out of pocket spending to 10 percent of income can substantially recuce total medical spending even though a substantial part of health outlays are incurred by families spending 10 percent or more of family income on health care.

The change in health care spending reduces the deadweight loss that now results because low co-insurance rates induce excessive consumption of health care. The combination of this reduction in the deadweight loss of excessive health care spending and the change in the risk of 
out of pocket spending represents a net welfare gain under most plausibie assumptions about demand elasticities and risk aversion.

Our estimates of the aggregate welfare gain from shifting to the 50-10 major risk policy (a 50 percent coinsurance rate and a 10 percent of income maximum out of pocket payment) range from $\$ 34$ billion with a low degree of risk aversion (a logarithmic utility function) and a low price elasticity of demand $(0.33)$ to $\$ 110$ billion with a higher degree of risk aversion (a constant relative risk aversion of 3 ) and higher demand elasticity $(0.5)$.

We show that, with a demand elasticity of 0.5 , universal government provision of this 50-10 major risk insurance policy could be financed by a combination of the additional tax revenue that would automatically result from the conversion to wage and salary income of the existing employer payments for health insurance and from the reduction in Medicare and Medicaid spending in parallel to the reduction in private health spending.

August 1994

mri.s 


\section{References}

Agency for Health Care Policy and Research (1991). The 1987 National Medical Expenditure Survey. Rockville, MD: Agency for Health Care Policy Research.

Arrow, K. J. (1963). "Uncertainty and the Welfare Economics of Medical Care," American Economic Review, 53:941-973.

Committee on Ways and Means (1993). 1993 Green Book. Washington, D.C.: U.S. Government Printing Office.

Congressional Budget Office (1993). Projection of National Health Expenditures: 1993 Update. Washington, D.C.: CBO.

Congressional Budget Office (1994). The Tax Treatment of Employment-Based Health Insurance. Washington, D.C.: CBO.

Cutler, David (1994). "Competition, Regulation, and Health Costs". Mimeo, Harvard University.

Gould, J.P. (1969). "The Expected Utility Hypothesis and the Selection of Optimal Deductibles for a Given Insurance Policy," Journal of Business, 42:143-151.

Borch, K.H. (1968). The Economics of Uncertainty. Princeton, N.J.: Princeton University Press.

Davis, K., and Russell, L.B. (1972). "The Substitution of Hospital Outpatient Care for Inpatient Care," Review of Economics and Statistics, 54:109-120.

Feldstein, M. (1971a). "A New Approach to National Health Insurance," The Public Interest, 23:93-105.

Feldstein, M. (1971b). "Hospital Cost Inflation: A Study of Nonprofit Price Dymamics," American Economic Review, 61:853-872.

Feldstein, M. (1973). "The Welfare Loss of Excess Health Insurance," Journal of Political Economy, 81:251-280.

Feldstein, M. and E. Allison (1974). "Tax Subsidies of Private Health Insurance: Distribution, Revenue Loss, and Effects, " in The Economics of Federal Subsidy Programs, pt 8, 977. 994. Washington, D.C.: U.S. Government Printing Office.

Feldstein, M., and B. Friedman (1977). "Tax Subsidies, the Rational Demand for Insurance, and the Health-Care Crisis," Journal of Public Economics, 7:155-178. 
Gruber, J. (1994). "The Incidence of Mandated Maternity Benefits," American Economic Review, 84:622-641.

Gruber, J., and A. Krueger (1991). "The Incidence of Mandated Employer-Provided Insurance: Lessons from Worker's Compensation Insurance," Tax Policy and the Economy 5, David Bradford, ed., 1991. Cambridge, MA: MIT Press.

Gruber, J., and J. Poterba (1994a). "The Elasticity of Demand for Health insurance: Evidence from the Self-Employed," Quarterly Journal of Economics, forthcoming August 1994.

Gruber, J., and J. Poterba (1994b). "Tax Subsidies to Health Insurance and Health Care". Mimeo, MIT Department of Economics.

Huth, S. (1991). "COBEA Costs Average 150\% of Active Costs," Employer Benefits Plan Review, 46:14-19.

Laffont, J. J. (1990). The Economics of Uncertainty and Information. Cambridge, MA: MIT Press.

Long, S., and M. S. Marquis (1992). "COBRA Continuation Coverage: Characterists of Enrollees and Costs in Three Plans," in U.S. Department of Labor, Pension and Welfare Benefits Administration, Health Benefits and the Workforce, Washington, D.C.: U.S. Government Printing Office.

Manning, W., et al. (1987). "Health Insurance and the Demand for Medical Care: Evidence from a Randomized Experiment," American Economic Review, 77:251-277.

Mossin, J. (1968). "Aspects of Rational Insurance Purchasing," Joumal of Political Economy, 76. part I:553-568.

Newhouse, J. (1993). Free For All: Lessons from the RAND Health Insurance Experiment. Santa Monica, CA: RAND Corporation.

Newhouse, J. et al. (1985). "Are Fee-for-Service Costs Increasing Faster than HMO Costs?," Medical Care, 23:960-966.

Pashigian, B. P., L. L. Schkade, and G. H. Menefee (1966). "The Selection of an Optimal Deductible for a Given Insurance Policy," Journal of Business, 39:35-44.

Pauly, M. (1974). 'Overinsurance and the Public Provision of Insurance: The Roles of Moral Hazard and Adverse Selection," Quarterly Journal of Economics, 88:44-62.

Phelps, C. (1992). Health Economics. New York: HarperCollins.

Phelps, C., and J. Newhouse (1974). "Consinurance, the Price of Time, and the Demand for 
Medical Services," Review of Economics and Statistics, 56:334-342.

Smith, V. L. (1968). "Optimal Insurance Coverage," Journal of Political Economy, 76:68-77.

Zeckhauser, R. (1970). "Medical Insurance: A Case Study of the Trade-off Between Risk Spreading and Apppropriate Incentives," Joumal of Economic Theory, 2:10-26.

Zeldes, S. (1989). "Consumption and Liquidity Constraints: An Empirical Investigation." Journal of Political Economy, 97, 305-346. 


\section{Appendix - "Synthetic" Population Estimates}

As noted in the text, a problem with our analysis by income class is that the sample of low income privately insured is not likely to be a representative group. Instead, these are most likely sick individuals whose health has impeded their earnings abilities; this is reflected in their high spending in Table 4.

We have therefore replicated our analysis with a "synthetic" sample which is designed to overcome this problem. The basic idea is to replace the individual's own spending with a random amount of spending which is not a function of income, but which reflects the demographic-adjusted spending distribution. The method for doing so is similar to that described in Part 4.2 of the text. We begin by dividing our sample into four demographic types of insurance units: single adults; single adults with children; couples; and couples with children. We rank each observation within a demographic type by spending, divide the ranked list into one hundred equal intervals, and assign a probability of 0.01 to each interval. We then assign each unit in that demographic group a spending level drawn randomly from that distribution. Both here and in section 4.2, we have expanded the sample so that there are a sufficient number of observations in each demographic group. We do so by replicating our original sample to inflate the size to 20,000 insurance units.

The results of this analysis are presented in Table A1, which parallels the earlier Table 4. The key difference between the tables is that the ex-ante distribution of spending is now flat until the highest income group, and then somewhat higher for that group; this reflects the demographic mix of the highest income group, which is more likely to contain (high spending) married couples with children. This contrasts with the U-shaped pattern seen in Table 4. 
The basic findings, however, are quite similar to those discussed in the context of Table 4: there is a substantial rise in out of pocket spending with income under the MRI plan, and the reduction in health care spending is much larger for higher income than for lower income individuals. Thus, while this approach eradicates the anomalous finding of much higher spending for low income individuals, the basic income distribution effects of an MRI-type plan are unchanged. 
Table 1: Didribution of Hewh Ces spandiat

\begin{tabular}{|c|c|c|c|c|c|}
\hline Spending Group & $\begin{array}{l}\text { Mean } \\
\text { Speradint }\end{array}$ & $\begin{array}{r}\text { Percent of bo } \\
\end{array}$ & 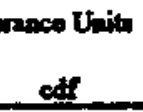 & Pucent of Tot & peeding \\
\hline $\begin{array}{l}\text { Undir } 500 \\
500-1000 \\
1000-1500 \\
1500-2000 \\
2000-2500 \\
2500-3000 \\
3000-3500 \\
3500-4000 \\
4000-4500 \\
4500-5000 \\
5000-6000 \\
6000-7000 \\
7000-8000 \\
8000-9000 \\
9000-10000 \\
10000-15000 \\
15000-20000 \\
20000-25000 \\
0 \mathrm{v}=25000\end{array}$ & $\begin{array}{r}151 \\
728 \\
1235 \\
1711 \\
2242 \\
2738 \\
3246 \\
3705 \\
1249 \\
4764 \\
5499 \\
6439 \\
7498 \\
8495 \\
9495 \\
12139 \\
17414 \\
22569 \\
52804\end{array}$ & $\begin{array}{l}38.9 \% \\
13.4 \% \\
8.5 \% \\
5.1 \% \\
3.5 \% \\
3.9 \% \\
2.7 \% \\
1.8 \% \\
1.8 \% \\
1.5 \% \\
2.7 \% \\
2.3 \% \\
1.7 \% \\
1.8 \% \\
1.1 \% \\
4.1 \% \\
1.8 \% \\
1.1 \% \\
2.7 \%\end{array}$ & $\begin{array}{l}30.9 \% \\
52.3 \% \\
60.9 \% \\
65.9 \% \\
69.4 \% \\
72.9 \% \\
75.6 \% \\
77.4 \% \\
79.2 \% \\
00.7 \% \\
93.4 \% \\
85.7 \% \\
97.4 \% \\
99.2 \% \\
90.3 \% \\
94.4 \% \\
96.2 \% \\
97.3 \% \\
100.0 \%\end{array}$ & $\begin{array}{r}1.5 \% \\
2.4 \% \\
2.6 \% \\
2.2 \% \\
2.0 \% \\
2.4 \% \\
2.2 \% \\
1.7 \% \\
1.9 \% \\
1.8 \% \\
3.5 \% \\
3.7 \% \\
3.2 \% \\
3.8 \% \\
2.6 \% \\
12.4 \% \\
7.7 \% \\
5.6 \% \\
36.1 \%\end{array}$ & $\begin{array}{r}1.5 \% \\
3.9 \% \\
6.5 \% \\
8.7 \% \\
10.7 \% \\
13.1 \% \\
15.3 \% \\
17.0 \% \\
13.9 \% \\
20.7 \% \\
24.5 \% \\
28.2 \% \\
31.4 \% \\
35.2 \% \\
37.5 \% \\
50.2 \% \\
57.9 \% \\
63.5 \% \\
100.0 \%\end{array}$ \\
\hline
\end{tabular}

Note: Extimutes refer to total eponding on phyicien and houpitul services in 1995 by the population under ase 65 Ses text for further deacription. 
Table 2: Diserlbulas of Ont - of - Pectut Health Cans Speadias

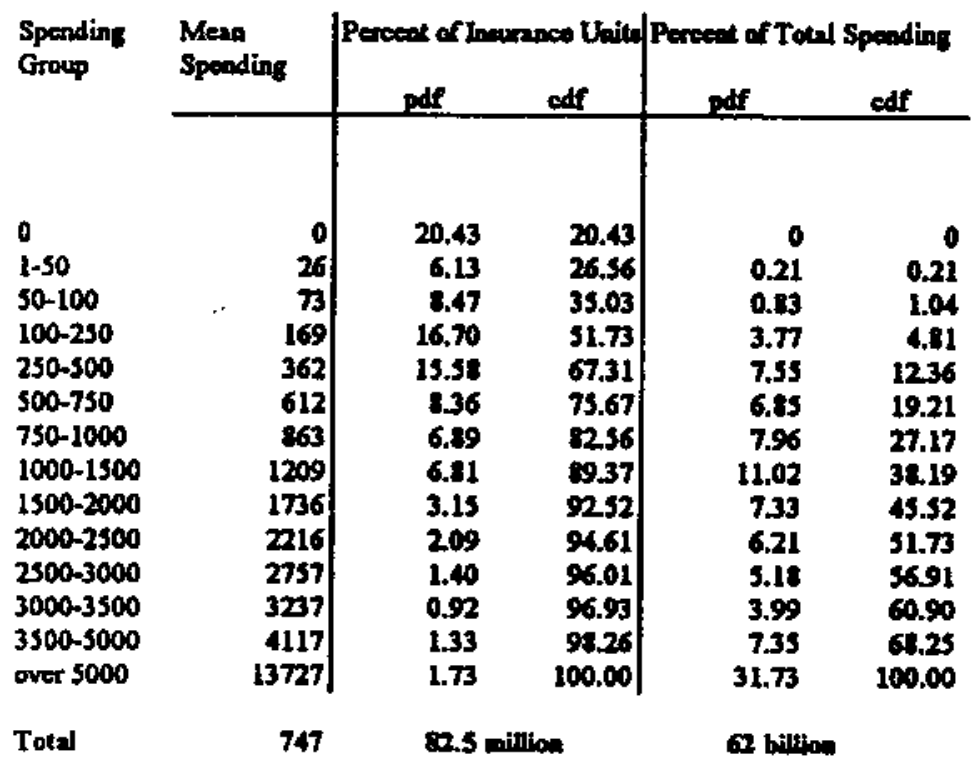

Note: Extimated refer to out of poctet upeoding on phyicins and bopital services in 1995 by the population under age 65 . See text for firther deacription. 
Table 3: Expenditure Effocts of Alterative Mrjor Risk Insurance Plass

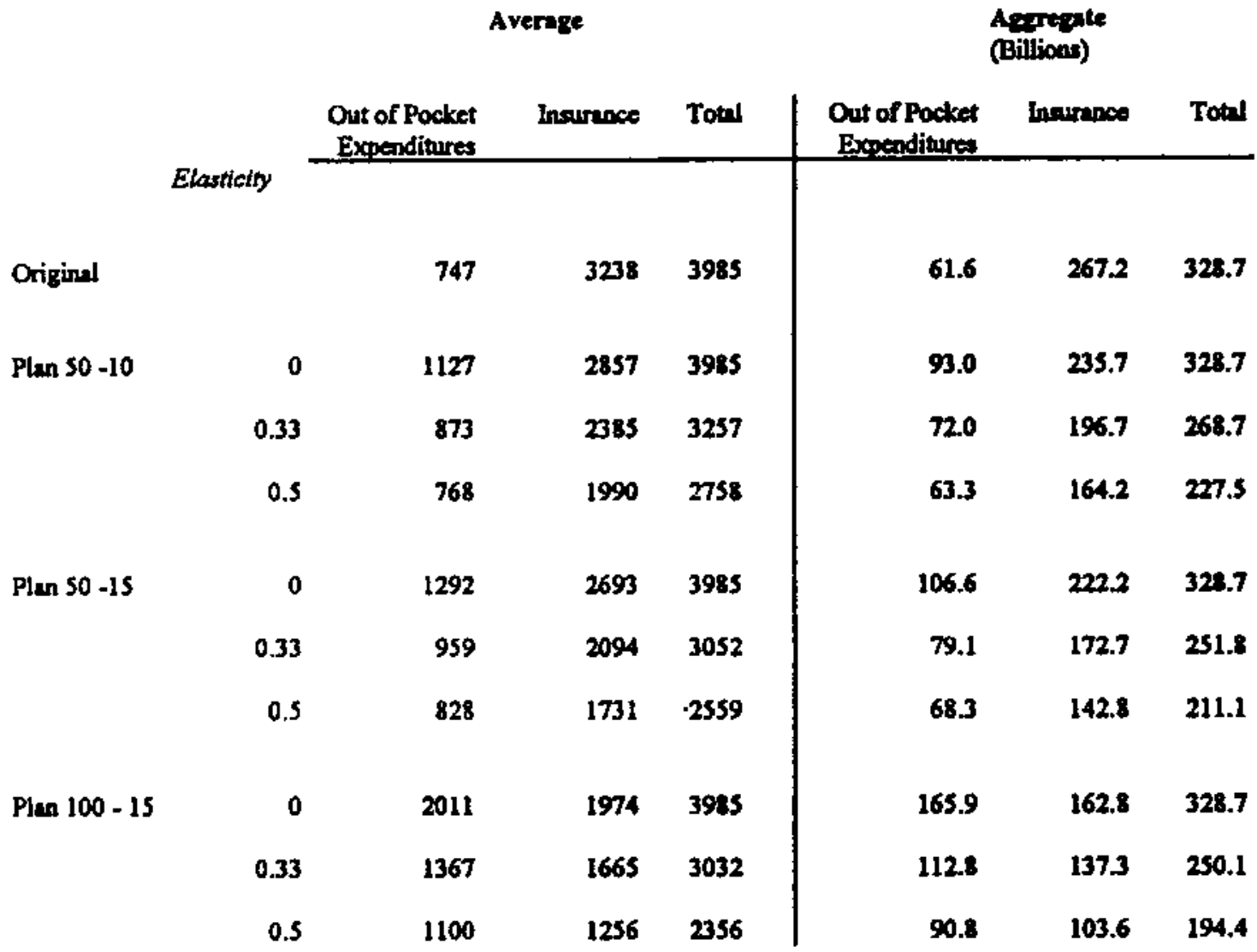

Note: All figures in 1995 dollars. "Avange" columns refic to caleulatione per insurance unit "Ageregate" columas refer to calculations for the netion as a whole, and they ere in billions of dollars. Soe text for further derails. 


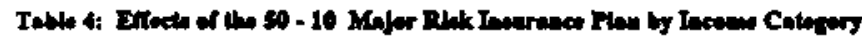

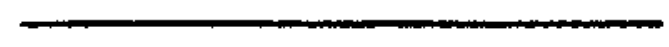

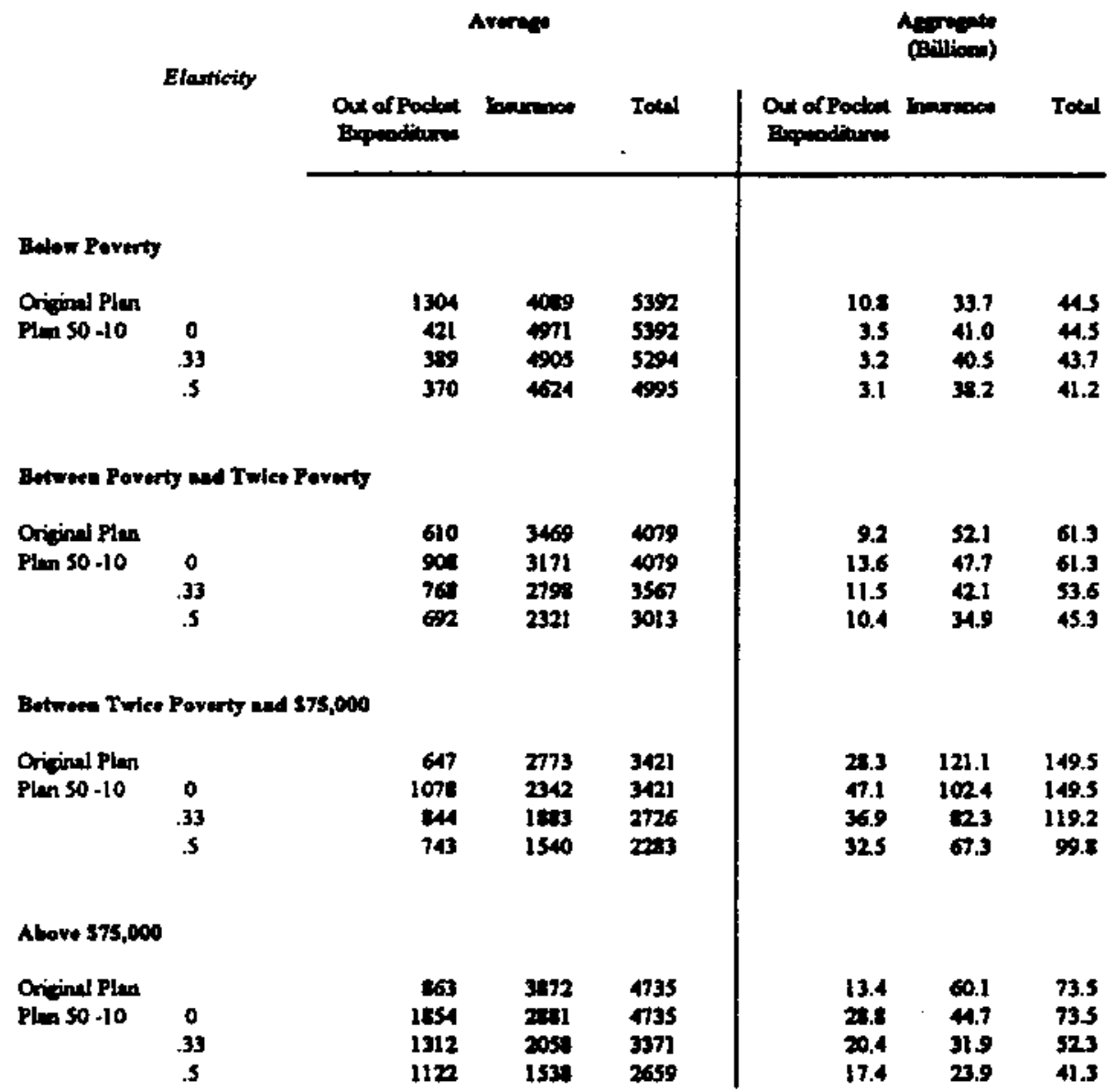

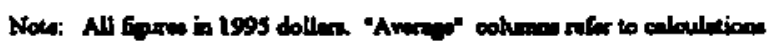

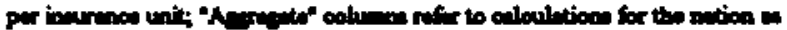

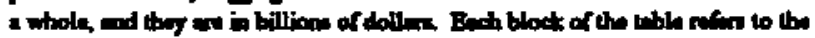

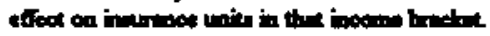




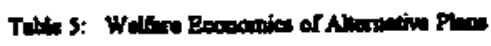

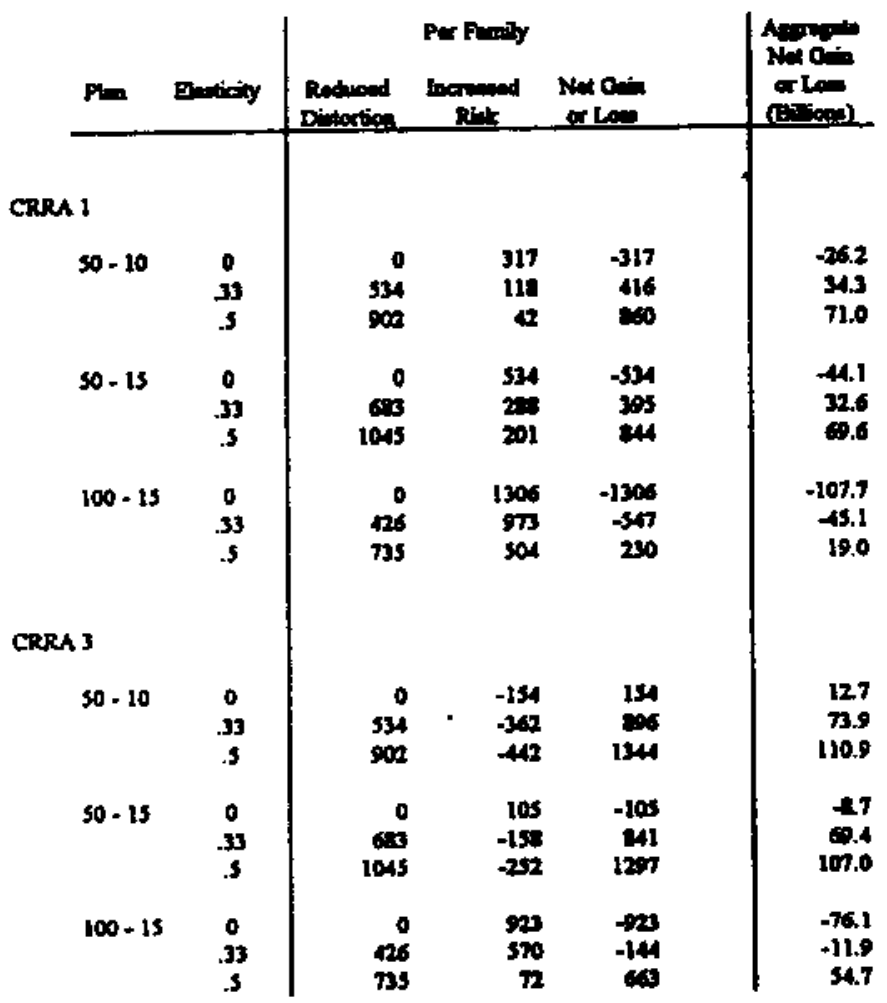

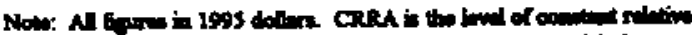

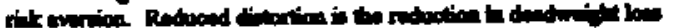

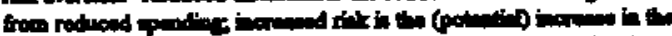

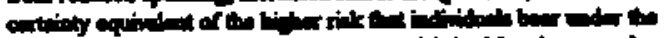

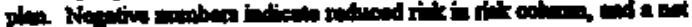

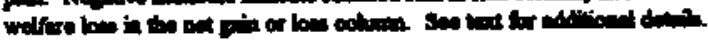




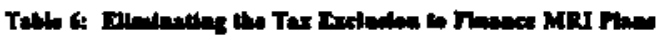

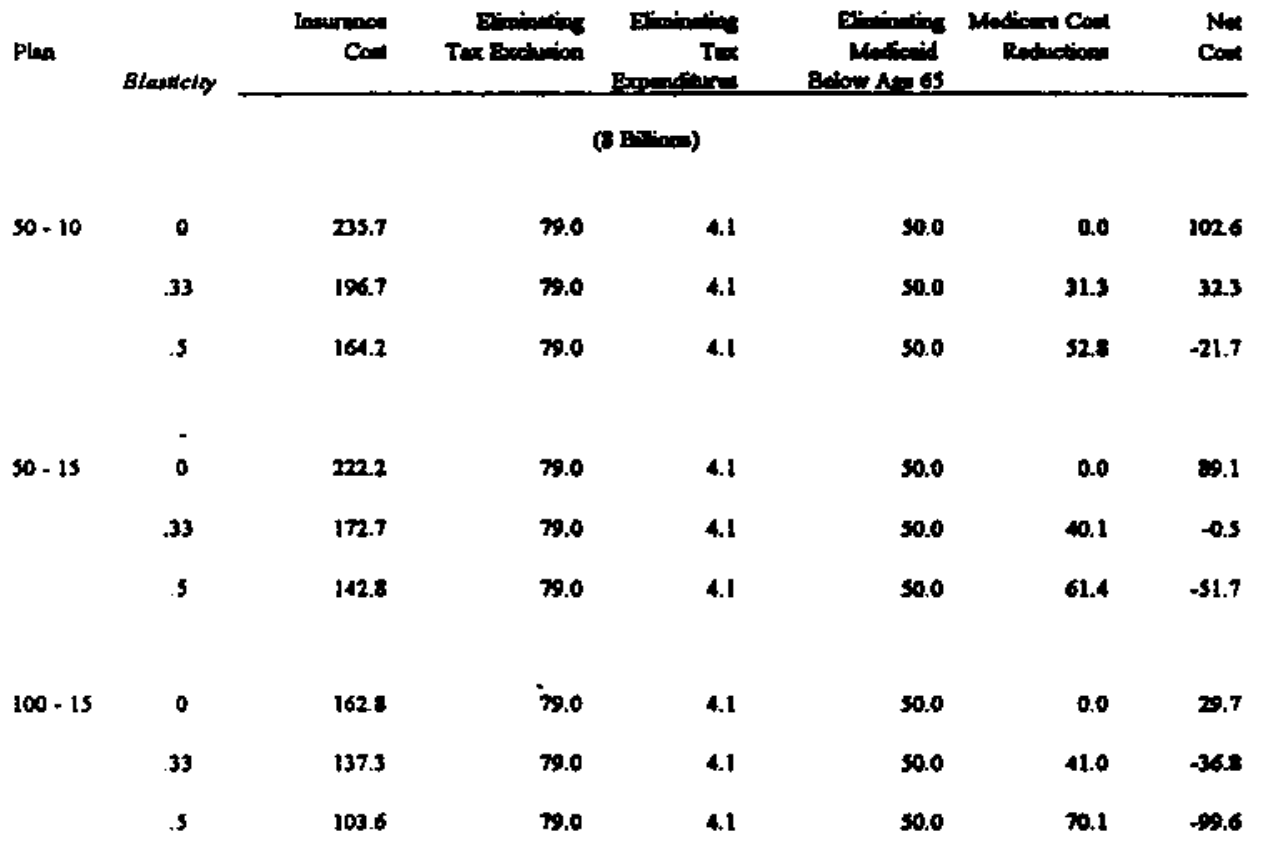

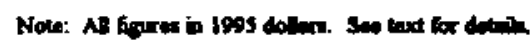




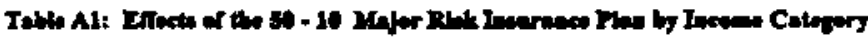

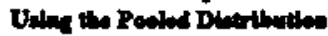

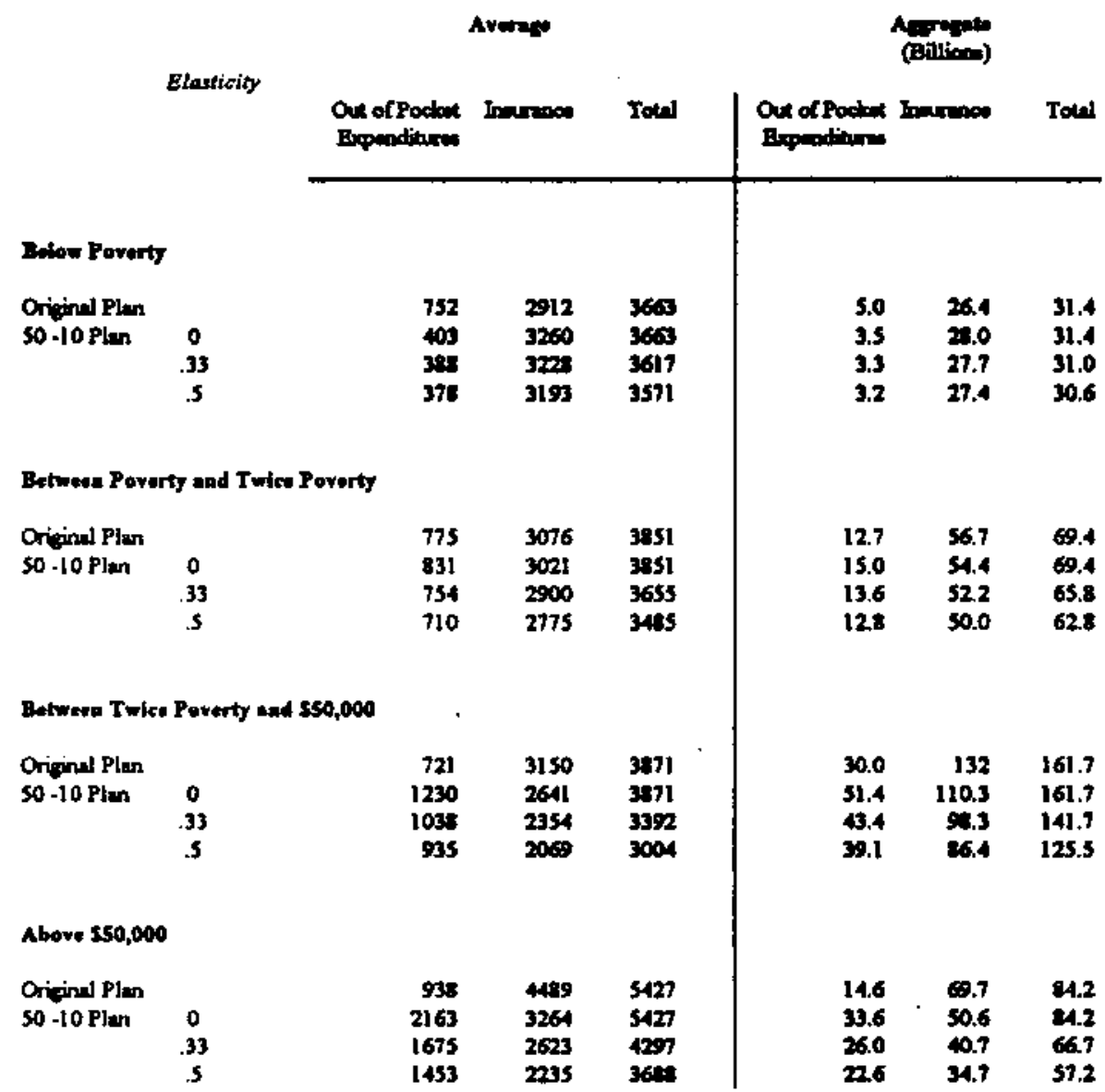

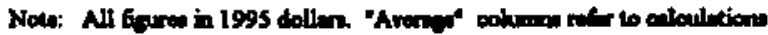

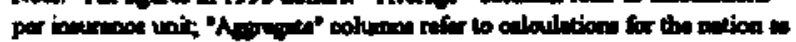

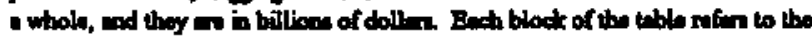

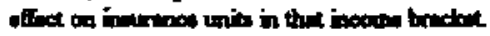


Figure 1

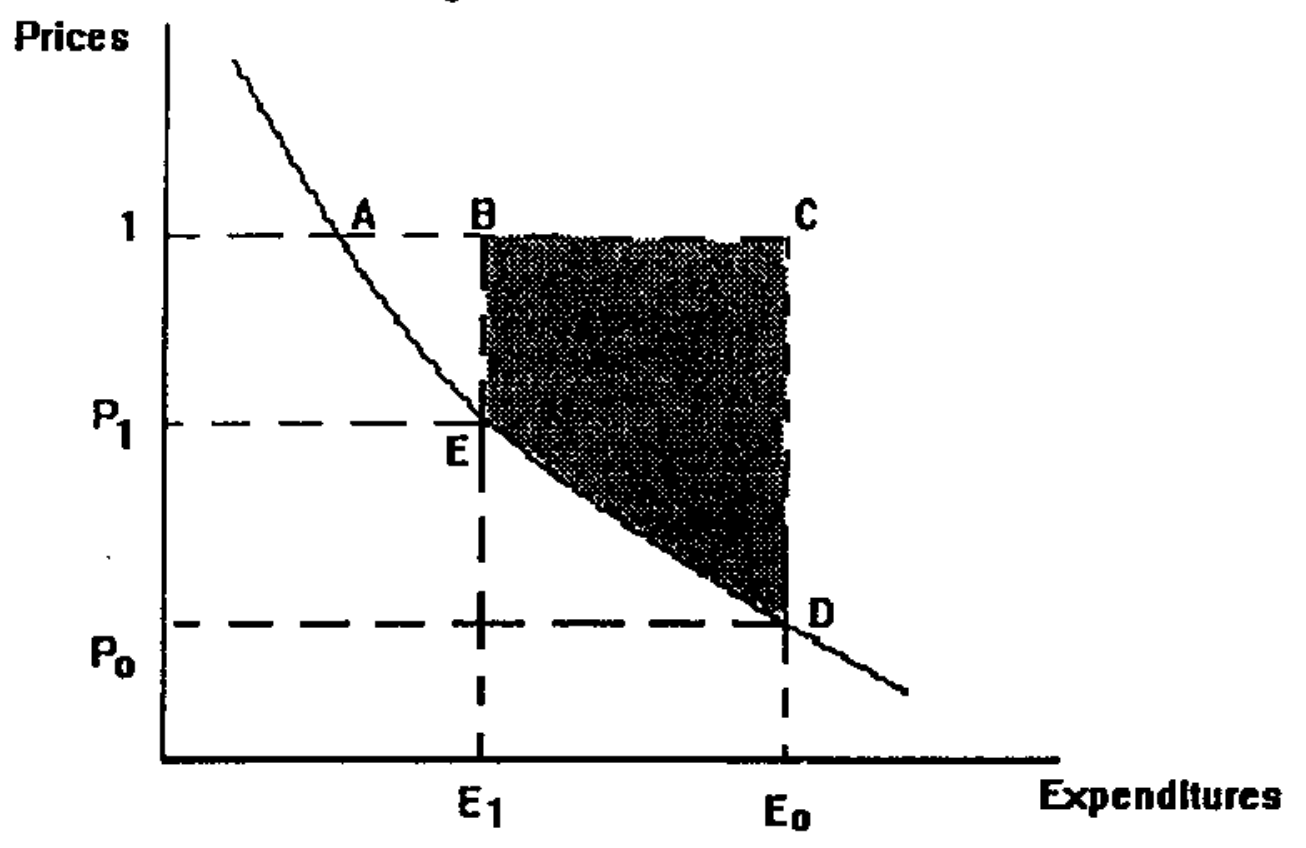

